\title{
Perspectives on the Phillips CPAP Recall
}

Disclaimer: The use, mention or depiction of any product, device, service or appliance shall not be interpreted as an endorsement, recommendation or preference by the AADSM. Any opinion expressed is solely the opinion of the individual, and not that of the AADSM.

On June 14, 2021, the Phillips Respironics voluntarily recalled a number of their continuous positive airway pressure (CPAP) and BiLevel PAP devices. ${ }^{1}$ We reached out to our members to hear how this recall has impacted their practice.

\section{WHAT ARE YOUR THOUGHTS ON THE RECENT PHILLIPS RECALL OF CPAP MACHINES? HAVE YOU SEEN ANY IMPACT OF THIS RECALL ON YOUR PRACTICE AND PATIENT INFLOW? WHAT, IF ANY, IMPACT DO YOU THINK THIS WILL CONTINUE TO HAVE ON YOUR PRACTICE IN THE FUTURE?}

"I am fortunate to work in a multidisciplinary model of care that integrates dental sleep medicine and sleep medicine in one clinic. This being said, we still have a subset of sleep physicians in our clinic who do not believe in oral appliance therapy and prescribe CPAP exclusively. The Phillips recall, and subsequent shortage of available CPAP machines, has forced them to re-evaluate oral appliances and how they can help meet the needs of their patients. I am seeing increased referrals from "appliancefriendly" physicians and new referrals from our "nonbelievers". Ultimately, I believe this will have a positive impact on dental sleep medicine, as physicians see their patients effectively treated, and in turn, reconsider OAT as first-line therapy."

\section{-Dr. Samantha Bohay, DMD, D.ABDSM}

"The Phillips CPAP recall has been disastrous for patient health and the providers who are trying to help them. Patients and providers have been left scrambling for alternative therapies to manage this potentially lifethreatening condition.

Patients have expressed to me that they feel misled about CPAP safety by the CPAP industry, which is especially frustrating after an often difficult road to reach compliance. Some patients question whether their CPAP contributed to other related health conditions. In addition, some payers continue to deny coverage for alternative therapies, including a custom oral appliance, for patients who have been victims of the CPAP recall.

In my practice I have seen a definite increase in patients seeking an oral appliance - a trend I anticipate will continue for at least another year. Fortunately, with our quality of staff, industry partners and systems, we have been able to adapt as a practice in our workflow to help this increase in patients."

\section{-Dr. Srujal H. Shah, DDS, D.ABDSM}

When news of the Phillips recall was first available in late June, I think it would be safe to say that dentists intimately involved in providing oral appliance therapy saw this as a situation that would result in an immediate increase in patient volume. Not only would more patients be seeking the alternative therapy of the oral appliance to replace their CPAP machine, but their need would also be immediate. Sleep dentists were surely thinking, "can we handle the surge of patients that might be forthcoming? Should we plan to temporize them to get the patients into treatment until we could turnaround and properly titrate their permanent appliance?" Well, three months into the recall once the dust settled, it seems that many of the sleep physicians and DME providers have been able to manage their patients without the need for much intervention from dentists. In my area, the majority of sleep physicians felt the benefit of maintaining their medically-at-risk patients with continued use of their machines far outweighed the risk of having what they perceived as minor airway irritation caused by breakdown of the sound abatement material. Patients with mild OSA and much less medical risk were given the option to just discontinue use of their PAP therapy or seek an alternative therapy.

With the medical sleep community internally managing the majority of their patients affected by the recall, the productive impact and additional patient flow to our group of practices was more insignificant than originally anticipated. I could foresee that OSA patients going forward who have done their due diligence in exploring their treatment options and learning of the PAP recall may be less inclined to choose CPAP as their treatment. The recall, along with the negative publicity surrounding it, may lend to having more patients consider oral appliance therapy as their primary treatment option.

$$
\text { -Dr. Michael F. Hnat, DMD, D.ABDSM }
$$


"Not all patients are aware of the Phillips recall for CPAP, Bilevel PAP, BiPAP, or BPAP Devices which was issued on June $14^{\text {th }}, 2021$. On the Phillips site, there are links to register affected devices if the user, prescriber, or distributor are aware. The FDA urges patients to not stop or change their ventilator use until they have talked to their health care provider. Alternative treatments such as an oral appliance have been proven to be efficacious for OSA. I believe that anyone using a positive airway pressure (PAP) device should know the name of the manufacturer and model in case situations like these arise.

So far, my patients haven't been impacted nor have we had any patients mentioning this situation. We are currently screening new patients and asking existing patients that have notified us of using a PAP device to inform them of the current recall.

This predicament has shown our office, and many others, that alternative treatments should be taken into account to always allow options due to possible unforeseeable circumstances. That being said, AADSM Qualified Dentists and Diplomates of the ABDSM are here to help by providing oral appliance therapy for sleeprelated breathing disorders. The future for our office will always be the same as the present, 'Guiding our patients towards achieving an optimal quality of life holds the utmost importance in our office."

-Dr. David Flamenco, DDS, ABDSM

\section{CITATION}

Perspectives on the Phillips CPAP recall. J Dent Sleep Med. 2021;8(4).

\section{REFERENCES}

1. Medical device recall notification: Philips Respironics sleep and respiratory care devices. Phillips Respironics. Accessed October 5, 2021. https://www.usa.philips.com/healthcare/e/sleep/communications/src-update
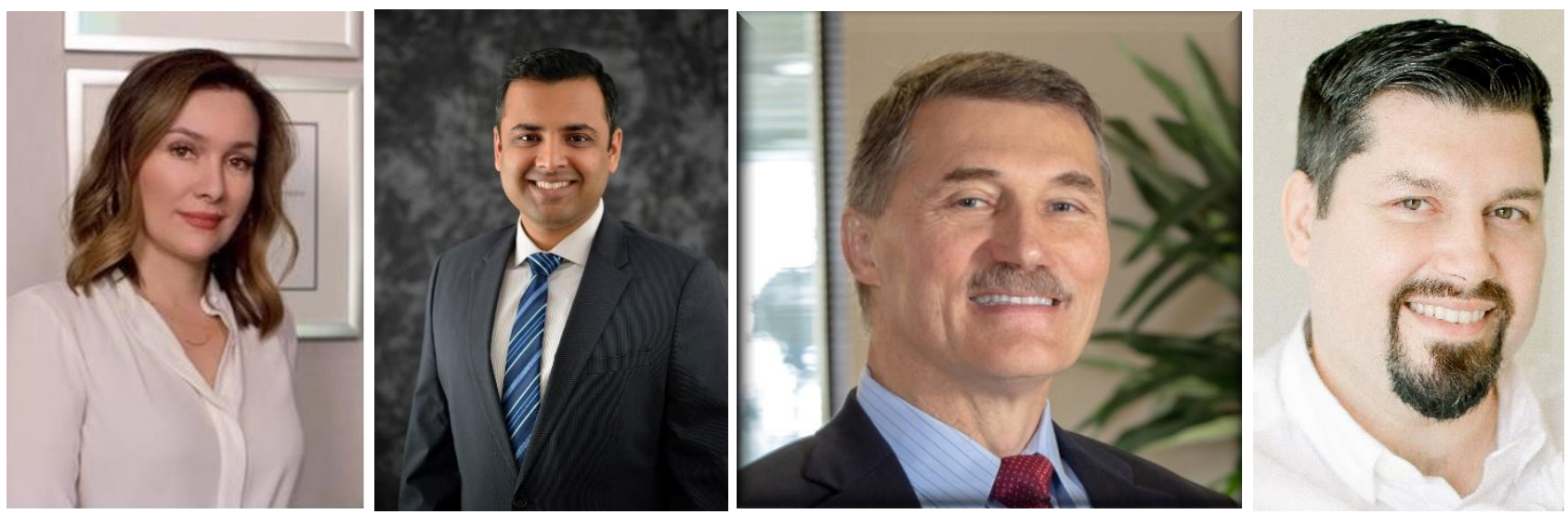

Left to Right: Dr. Samantha Bohay, Dr. Srujal H. Shah, Dr. Michael F. Hnat, Dr. David Flamenco 